\title{
Morphine Spinal Block Anesthesia in Patients Who Undergo an Open Hemorrhoidectomy: A Prospective Analysis of Pain Control and Postoperative Complications
}

\author{
Hélio Moreira Jr, José PT Moreira, Raniere R Isaac, Onofre Alves-Neto ${ }^{1}$, Thiago AC Moreira ${ }^{1}$, \\ Tiago HM Vieira ${ }^{1}$, Andressa MS Brasil \\ Department of Surgery, Colorectal Service, School of Medicine of the Federal University of Goias, Goias; ${ }^{1}$ Department of Surgery, \\ Anesthesiology Service, School of Medicine of the Federal University of Goias, Goias, Brazil
}

Purpose: This study evaluated the use of adding morphine to bupivacaine in spinal anesthesia for pain control in patients who underwent an open hemorrhoidectomy.

Methods: Forty patients were prospectively selected for an open hemorrhoidectomy at the same institution and were randomized into two groups of 20 patients each: group 1 had a spinal with $7 \mathrm{mg}$ of heavy bupivacaine associated with $80 \mu \mathrm{g}$ of morphine $(0.2 \mathrm{mg} / \mathrm{mL})$. Group 2 had a spinal with $7 \mathrm{mg}$ of heavy bupivacaine associated with distilled water, achieving the same volume of spinal infusion as that of group 1. Both groups were prescribed the same pain control medicine during the postoperative period. Pain scores were evaluated at the anesthetic recovery room and at 3, 6, 12, and 24 hours after surgery. Postoperative complications, including pruritus, nausea, headaches, and urinary retention, were also recorded. Results: There were no anthropometric statistical differences between the two groups. Pain in the anesthetic recovery room and 3 hours after surgery was similar for both groups. However, pain was better controlled in group 1 at 6 and 12 hours after surgery. Although pain was better controlled for group 1 after 24 hours of surgery, the difference between the groups didn't achieved statistical significance. Complications were more common in group 1 . Six patients $(6 / 20)$ presented coetaneous pruritus and 3 with $(3 / 20)$ urinary retention.

Conclusion: A hemorrhoidectomy under a spinal with morphine provides better pain control between 6 and 12 hours after surgery. However, postoperative complications, including cutaneous pruritus (30\%) and urinary retention (15\%), should be considered as a negative side of this procedure.

Keywords: Postoperative pain; Hemorroidectomy; Urinary retention

\section{INTRODUCTION}

The term hemorrhoids comes from Greek (hemos, blood; rhoos,

Received: August 23, 2013 - Accepted: November 1, 2013

Correspondence to: Helio Moreira Jr, M.D.

Department of Surgery, Colorectal Service School of Medicine, Federal University of Goiás, Avenida B, N.435, Setor Oeste, Goiânia Goiás 74110-030, Brazil

Tel: +556232259300, Fax: +556232259300

E-mail:drhmjr@gmail.com

(C) 2014 The Korean Society of Coloproctology

This is an open-access article distributed under the terms of the Creative Commons Attribution NonCommercial License (http://creativecommons.org/licenses/by-nc/3.0) which permits unrestricted noncommercial use, distribution, and reproduction in any medium, provided the original work is properly cited. pour in) and describes a very common symptom of patients with hemorrhoidal disease [1]. Hemorrhoids involve the loss of connective tissue that supports the hemorrhoidal plexus, followed by dilatation of the vessels $[2,3]$. The real incidence of hemorrhoids remains uncertain and may vary from $4.4 \%$ to $88 \%$ of the population, depending on the study design $[4,5]$. The condition may be associated with inflammation, bleeding or thrombosis. Surgical treatment is indicated for the clinical management of refractory cases, which usually involve larger, symptomatic hemorrhoids associated with mucosal prolapse. Postoperative pain is a major concern for the patients and causes a delay in the decision to undergo surgery, even though the disease itself is very uncomfortable. Therefore, when surgery is finally undertaken, a more extensive operation, which ultimately results in a higher morbidity rate, 
including worse postoperative pain and prolonged disability, is necessary [6].

In Brazil, in the majority of cases, hemorrhoidectomies are performed under a spinal subarachnoid block or local anesthesia [7]. Spinal anesthesia with bupivacaine and morphine, as it provides an excellent analgesia, seems to be an interesting option. However, the use of opioids in the neuroaxis may present with adverse events, including nausea, vomiting, headache, urinary retention and respiratory depression [8].

Many factors might be involved in postoperative pain after a hemorrhoidectomy: surgical technique (open, closed, anopexy, etc.), the used energy source (cold blade, monopole or bipolar electrocautery, laser, etc.), the use of antibiotics, and the used anesthesia technique. Better pain control may result in more comfort for the patient, a shorter period of hospitalization, lower costs, and diminished disability $[9,10]$.

\section{METHODS}

The aim of the study was to compare the analgesic quality and the morbidity during the postoperative period of patients who underwent a hemorrhoidectomy under a bupivacaine spinal subarachnoid block either with or without combined morphine. The study was approved by the Ethical Committee at the Hospital das Clinicas, and patients signed an informed consent form. Forty patients were included in this study. Inclusion criteria were being over 18 years old and having large mixed hemorrhoids (minimal of 3 piles and with grade III or IV internal hemorrhoids). Patients with other anorectal diseases were excluded. All patients were prospectively randomized into two groups of 20 individuals each. The anesthetics were manipulated by a single anesthesiologist who delivered the syringes to another blinded anesthesiologist in a proper aseptic way. A third doctor who performed evaluations during the postoperative period was also unaware of which anesthesia each patient had received.

All patients were monitored using cardioscopy, pulse oximetry, and noninvasive arterial blood pressure measurements. A peripheral line was achieved with a $20-\mathrm{G}$ catheter, and intravenous sedation was done with $3 \mathrm{mg}$ of midazolam. All patients received $2 \mathrm{~g}$ of cefazolin sodium intravenously as an antibiotic prophylaxis. Nausea and vomiting prophylactic medication was also administered (10 mg of dexamethasone, $8 \mathrm{mg}$ of ondansetron and $10 \mathrm{mg}$ of bromopride.

Group 1 had spinal subarachnoid block with $7 \mathrm{mg}$ of heavy bupivacaine and $80 \mu \mathrm{g}$ of morphine $(0.2 \mathrm{mg} / \mathrm{mL})$ aspirated into a dissymmetric syringe. Group 2 had spinal anesthesia with $7 \mathrm{mg}$ of heavy bupivacaine in distilled water, ending up with the same infusion volume as that of group 1. Both groups had postoperative analgesia with Metamizole, $2 \mathrm{~g}$ Endo Venous (EV) every 6 hours, or tramadol chlorhydrate, $100 \mathrm{mg}$ EV every 8 hours, if requested by the patient. All patients were discharged with prescriptions of Metamizole, 500 mg every 6 hours, and codeine + acetaminophen
(Tylex, JANSSEN, Janssen-Cilag Farmacêutica Ltda, São Paulo, Brazil), 30 mg every 4 hours.

Postoperative pain was evaluated immediately after the patient had been admitted to the recovery room and at 3, 6, 12, and 24 hours after the surgical procedure. A numeric/verbal scale varying from $0-10$, with 10 being extreme pain, was used to measure the pain [11]. Other complications, including pruritus, nausea, vomiting, headache, and urinary retention were also recorded.

\section{RESULTS}

The mean age of group 1 patients was $40.5 \pm 12.6$ years old, and $70.6 \%$ were female. Group 2 patients had $44.4 \%$ female patients with a mean age of $46.1 \pm 14.3$ years old. The mean weights of groups 1 and 2 were $71.7 \mathrm{~kg}$ and $69.1 \mathrm{~kg}$, respectively. American Society of Anesthesiologists (ASA) classifications were similar for the two groups (70\% and 66.7\% were ASA 1 for groups 1 and 2, respectively). The Student t-test and chi-square test showed no statistical differences between the genders, ages, weight, and ASA classification group (Tables 1,2).

The periods of time for the patient to be discharged from the anesthetic recovery room (ARR) and to have spontaneous diuresis were similar between the two groups. Group 1 was discharged from the ARR after $16.8 \pm 13.6$ minutes, on average, and presented first diuresis after $6 \pm 1.3$ hours. On the other hand, group 2 was discharged from the ARR after $27 \pm 17.7$ minutes and presented first diuresis after $7.3 \pm 2.4$ hours. However, neither of these parameters showed a statistically significant difference.

No group 1 patient complained of postoperative pain while in the ARR. One group 2 patients reported mild pain (varying from 0 to 1 ) while in the ARR. The Fisher exact test showed no statistical difference between the two groups (Table 3). Group 1's pain scores varied from 0 to 4 at 3 hours after surgery, with $41.2 \%$ indicating a score of 2. Group 2's pain scores also varied from 0 and 4 at 3 hours after surgery, but $50 \%$ indicated no pain. The chisquare test showed no statistical difference between the two groups (Table 4).

At 6 hours after surgery, group 1's pain scores were very similar

Table 1. Gender and ASA distribution of groups 1 and 2

\begin{tabular}{lccc}
\hline Variable & Group 1 $(n=17)$ & Group 2 $(n=18)$ & P-value \\
\hline Gender & & & 0.111 \\
Male & $5(29.4)$ & $10(55.6)$ & \\
Female & $12(76.6)$ & $8(44.4)$ & \\
ASA class & & & 0.503 \\
1 & $12(70.6)$ & $12(66.7)$ & \\
2 & $4(23.5)$ & $6(33.3)$ & \\
3 & $1(5.9)$ & $0(0)$ & \\
\hline
\end{tabular}

Chi-square test.

ASA, American Society of Anesthesiologists. 
Volume 30, Number 3, 2014

Ann Coloproctol 2014;30(3):135-140

Table 2. Mean age, weight, aldrede, and spontaneous diuresis and standard deviation with confidence intervals

\begin{tabular}{lcccc}
\hline Factor & No. & Mean $\pm \mathrm{SD}$ & $95 \% \mathrm{Cl}$ & P-value \\
\hline Age (yr) & & & & 0.232 \\
Group 1 & 17 & $40.5 \pm 12.6$ & $34.0-47.0$ & \\
Group 2 & 18 & $46.1 \pm 14.3$ & $39.0-52.2$ & \\
Weight (kg) & & & & 0.532 \\
Group 1 & 17 & $71.7 \pm 13.2$ & $64.9-78.5$ & \\
Group 2 & 18 & $69.1 \pm 11.7$ & $63.3-74.9$ & \\
Aldrede 10 (min) & & & & 0.075 \\
Group 1 & 17 & $16.8 \pm 13.6$ & $9.8-23.7$ & \\
$\quad$ Group 2 & 18 & $27.0 \pm 17.7$ & $17.2-36.8$ & \\
Spontaneous diuresis & & & & 0.149 \\
$\quad$ Group 1 & 17 & $6.0 \pm 1.3$ & $1.3-7.0$ & \\
Group 2 & 18 & $7.3 \pm 2.4$ & $2.4-8.7$ & \\
\hline
\end{tabular}

Chi-square test.

$\mathrm{SD}$, standard deviation; $\mathrm{Cl}$, confidence interval.

Table 3. Patient pain score at the anesthetic recovery room

\begin{tabular}{lccc}
\hline & Group 1 $(\mathrm{n}=17)$ & Group 2 $(\mathrm{n}=18)$ & P-value \\
\hline Pain scale (0-10) & & & 0.782 \\
0 & $17(100)$ & $17(94.4)$ & \\
1 & $0(0)$ & $1(5.6)$ & \\
\hline
\end{tabular}

Chi-square test.

Table 4. Patient pain score 3 hours after surgery

\begin{tabular}{lccc}
\hline & Group 1 $(\mathrm{n}=17)$ & Group 2 $(\mathrm{n}=18)$ & P-value \\
\hline Pain scale (0-10) & & & 0.782 \\
0 & $4(23.5)$ & $9(50.0)$ & \\
1 & $6(35.5)$ & $4(22.2)$ & \\
2 & $7(41.2)$ & $4(22.2)$ & \\
4 & $0(0)$ & $1(5.6)$ & \\
\hline
\end{tabular}

Chi-square test.

to what was described at 3 hours after surgery, varying from 0 to 4 . However, group 2 anal pain scores varied from 1 to 6 , and $22.3 \%$ reported a pain score equal or over 5 . Moreover, only $17.6 \%$ of group 1 patients indicated a pain score of 4 vs. $27.8 \%$ from group 2. The chi-square test showed a statistical difference between these two groups $(\mathrm{P}=0.01)$ (Table 5$)$.

Group 1's anal pain scores at 12 hours after surgery varied from 1 to 6 while group 2 anal pain scores varied between 1 and 10, and the scores were more evenly distributed. About one third of group 2 patients presented with moderate to severe anal pain (pain score equal or over 5). A larger number of group 1 patients (76.5\%) indicated a score of 1 or 2 while only $33.4 \%$ of group 2 reported such mild anal pain. The chi-square test showed again a
Table 5. Patient pain score 6 hours after surgery

\begin{tabular}{lccc}
\hline & Group 1 $(\mathrm{n}=17)$ & Group 2 $(\mathrm{n}=18)$ & P-value \\
\hline Pain scale (0-10) & & & 0.010 \\
0 & $1(5.9)$ & $0(0)$ & \\
1 & $4(23.5)$ & $1(5.6)$ & \\
2 & $7(41.2)$ & $5(27.8)$ & \\
3 & $2(11.8)$ & $3(16.7)$ & \\
4 & $3(17.6)$ & $5(27.8)$ & \\
5 & $0(0)$ & $1(5.6)$ & \\
6 & $0(0)$ & $3(16.7)$ & \\
\hline
\end{tabular}

Chi-square test.

Table 6. Patient pain score 12 hours after surgery

\begin{tabular}{llcc}
\hline & Group 1 $(\mathrm{n}=17)$ & Group 2 $(\mathrm{n}=18)$ & P-value \\
\hline Pain scale (0-10) & & & 0.043 \\
1 & $5(29.4)$ & $3(16.7)$ & \\
2 & $8(47.1)$ & $3(16.7)$ & \\
3 & $1(5.9)$ & $2(11.1)$ & \\
4 & $1(5.9)$ & $4(22.2)$ & \\
5 & $1(5.9)$ & $2(11.1)$ & \\
6 & $1(5.9)$ & $1(5.6)$ & \\
7 & $0(0)$ & $1(5.6)$ & \\
8 & $0(0)$ & $1(5.6)$ & \\
10 & $0(0)$ & $1(5.6)$ & \\
\hline
\end{tabular}

Chi-square test.

Table 7. Patient pain score 24 hours after surgery

\begin{tabular}{lccc}
\hline & Group 1 $(\mathrm{n}=17)$ & Group 2 $(\mathrm{n}=18)$ & P-value \\
\hline Pain scale (0-10) & & & 0.014 \\
0 & $1(5.9)$ & $0(0)$ & \\
1 & $5(29.4)$ & $1(5.6)$ & \\
2 & $7(41.2)$ & $8(22.2)$ & \\
3 & $4(23.5)$ & $3(16.7)$ & \\
4 & $0(0)$ & $4(44.4)$ & \\
5 & $0(0)$ & $2(11.1)$ & \\
\hline
\end{tabular}

Chi-square test.

statistical difference between the two groups $(\mathrm{P}=0.041)$ (Table 6). Finally, group 1's anal pain scores 24 hours after surgery varied from 0 to 3, and a larger number of patients (41.2\%) indicated a score of 2. Group 2's anal pain scores varied between 1 and 5, and the most common anal pain score was 4 (44.4\%). While $54.5 \%$ of group 2 reported an anal pain score of 4 or 5 , no patient reported that intensity of pain on group 1 . The chi-square test showed again a statistical difference between the two groups $(\mathrm{P}=$ 0.041), demonstrating again a better quality of analgesia for group 
Table 8. Patients adverse events after surgery

\begin{tabular}{lccc}
\hline Variable & Group 1 $(\mathrm{n}=17)$ & Group 2 $(\mathrm{n}=18)$ & P-value \\
\hline Pruritus & & & 0.008 \\
No & $11(64.7)$ & $18(100)$ & \\
Yes & $6(35.3)$ & $0(0)$ & \\
Nausea and vomiting & & & 0.135 \\
No & $15(88.2)$ & $16(88.9)$ & \\
Yes & $2(11.8)$ & $2(11.1)$ & \\
Urinary retention & & & 0.104 \\
No & $14(82.4)$ & $18(100)$ & \\
Yes & $3(17.6)$ & $0(0)$ & \\
\hline
\end{tabular}

Chi-square test.

1 (Table 7).

The most common complication was cutaneous pruritus (6 cases), followed by nausea and vomiting (4 cases) and urinary retention ( 3 cases) (Table 8 ). All patients with pruritus and urinary retention were from group 1 (35.3\% and $17.6 \%$, respectively). The Kolmogorov Smirnov test showed a statistically significant difference between the two groups for the incidence of pruritus $(\mathrm{P}=$ 0.008). However, the difference between the two groups for urinary retention did not reach statistical significance $(\mathrm{P}=0.104)$. Two patients in each group presented with nausea and vomiting.

\section{DISCUSSION}

Postoperative pain remains a great challenge in surgery despite the outstanding advances observed over the last century. The standard for pain care is the use of an effective drug with minimal adverse effects. Minimally-invasive abdominal surgery also represents an advance in pain control. New surgical techniques for hemorrhoids, such as an anorectopexy with circular staples, also result in a more comfortable postoperative period with minimal anal pain. However, for the majority of patients with hemorrhoids with indication for surgical treatment, the standard procedure remains the open or the closed hemorrhoidectomy, where pain represents a major concern. The control of postoperative anal pain depends on various aggravating factors, including emotional condition, the number of excised hemorrhoidal piles, the source of energy used for excision (scissors, electrocautery, laser, etc.), the types of pre- and postoperative pain medication, the use of antibiotics, post-operative bowel function, and individual pain threshold [12-14].

The use of morphine for a spinal block is apparently an efficient method of analgesia. The drug connects to specific receptors at the posterior horn of the spinal cord. It prevents pain transmission in a way similar to the effect of endorphins, and its effect is sustained for up to 24 hours after surgery due to its hydrophilic property [15]. However, as with any other medication, it has ad- verse effects, such as respiratory depression, nausea and vomiting, cutaneous pruritus, and urinary retention.

Urinary retention may occur after a hemorrhoidectomy due to different factors, including temporary detrusor muscle dysfunction, urethral spasm secondary to anal pain, and excessive preand postoperative IV fluids [16-19]. It has been shown to increase with age, with the risk being 2.4 times larger in patients over 50 years of age. A higher incidence of pain has been reported in men. The incidence of POUR after anorectal surgery ranges from $1 \%$ to $52 \%$ [20-25].

The inclusion of morphine in the spinal block increases the risk of urinary retention due to reminiscent sacral parasympathetic blockage, which will remain until it reaches the third sacral segment $[26,27]$. Different epidural opioids results in different urodynamic effects [28]. Sufentanil and fentanyl are more lipophilic than morphine, so they undergo greater systemic uptake. Therefore, they undergo less rostral spread in the central nervous system and have less influence on the urodynamics $[29,30]$. The hydrophilic nature of morphine delays its systemic uptake, resulting in a higher concentration of the drug in the lumbar region. As a result, better analgesia comes with more inhibition of the neurons controlling the bladder. For similar reasons, the use of buprenorphine in a spinal block is associated with a smaller risk of urinary retention when compared to a spinal block with morphine [29].

Urinary retention is an unpleasant experience for the patient that should be avoided as bladder catheterization might be needed, which may result in bladder overdistention, urinary tract infection, catheter-related complications, increased hospital stay, and increased general costs [31]. Prevention of urinary retention in patients who underwent a spinal block with morphine, with interesting clinical outcomes, has been reported in the literature. Borges and de Araújo [32] conducted an observational study of 26 patients who underwent surgical and obstetric procedures under a spinal block with $0.1 \mathrm{mg}$ of morphine and developed urinary retention. Fractionated doses of $12.5 \mathrm{mg}$ of betanecol taken orally were used every hour for 4 hours, totaling $50 \mathrm{mg}$. They concluded that betanecol might be a good co adjuvant for treating spinalblock morphine-induced urinary retention as it was effective for 14 patients $(53.8 \%)$. In our study, urinary retention occurred only in group 1 (3/17 cases, $17.3 \%)$. Although no cases were reported in group 2, statistical analysis failed to reveal any significant difference between the two groups. A larger number of patients would probably be necessary to properly address this matter.

Although better pain control has clearly been demonstrated between 6 and 24 hours after a hemorrhoidectomy when morphine is added to the spinal block, its benefits of its routine use remain unclear. Because postoperative pain persists over 7 to 10 days after surgery, most of the postoperative pain period will not be affected by the morphine in the spinal block. Appropriate oral postoperative pain-control medications are mainly responsible for the patient's postoperative well being. There is no doubt that pain after surgery should be immediately recognized and properly treated 
as it might evolve into chronic postoperative pain, disability, psychological trauma, and residue fissure, resulting in a higher cost [33]. However, the rational for morphine use in a spinal block for surgical treatment of hemorrhoids, i.e., whether the benefit of a short period of pain control is worth the risk of urinary retention and cutaneous pruritus, should be discussed with the patient.

In conclusion, a spinal subarachnoid block with bupivacaine and morphine for patients who underwent an open hemorrhoidectomy resulted in better pain control between 12 and 24 hours after surgery when compared to a control group who underwent the same surgery and received a spinal block with only bupivacaine. However, the risk of cutaneous pruritus was higher for the group that used morphine. Moreover, the use of morphine on spinal blocks resulted in a potential risk of postoperative urinary retention.

\section{CONFLICT OF INTEREST}

No potential conflict of interest relevant to this article was reported.

\section{REFERENCES}

1. Santos HA. Doença hemorroidária. In: Cruz GM. Livro texto "Coloproctologia", Vol. II - "Coloproctologia - Propedêutica Nosológica”. Rio de Janeiro: Editora Revinter; 1999. p. 1139-56.

2. Thomson WH. The nature of haemorrhoids. Br J Surg 1975;62: 542-52.

3. Haas PA, Fox TA Jr, Haas GP. The pathogenesis of hemorrhoids. Dis Colon Rectum 1984;27:442-50.

4. Loder PB, Kamm MA, Nicholls RJ, Phillips RK. Haemorrhoids: pathology, pathophysiology and aetiology. Br J Surg 1994;81:94654.

5. Haas PA, Haas GP, Schmaltz S, Fox TA Jr. The prevalence of hemorrhoids. Dis Colon Rectum 1983;26:435-9.

6. Borba MR, Sobrado CW Jr, Sokol S. Hemorroidectomia pela técnica fechada (Técnica de Sokol) - análise de 322 doentes. Rev Bras Coloproct 1997;17:98-100.

7. Cruz GM. Livro texto "Coloproctologia”, Vol. II - "Coloproctologia - Propedêutica Nosológica”. Rio de Janeiro: Editora Revinter; 1999.

8. Cruz GM. Livro texto "Coloproctologia”, Vol. III - "Coloproctologia - Terapêutica”. Rio de Janeiro: Editora Revinter; 2000.

9. Iwagaki H, Higuchi Y, Fuchimoto S, Orita K. The laser treatment of hemorrhoids: results of a study on 1816 patients. Jpn J Surg 1989;19:658-61.

10. Jensen DM, Jutabha R, Machicado GA, Jensen ME, Cheng S, Gornbein J, et al. Prospective randomized comparative study of bipolar electrocoagulation versus heater probe for treatment of chronically bleeding internal hemorrhoids. Gastrointest Endosc 1997;46:435-43.

11. Neto OA. Livro texto. In: Neto OA, Costa CM, Siqueira JT, Teixeira MJ. Dor Princípios e Práticas. Porto Alegre: ARTMED; 2009. p. $370-72$

12. Kamphuis ET, Ionescu TI, Kuipers PW, de Gier J, van Venrooij GE, Boon TA. Recovery of storage and emptying functions of the urinary bladder after spinal anesthesia with lidocaine and with bupivacaine in men. Anesthesiology 1998;88:310-6.

13. Braum Filho LJ, Casado MR. Analgesia x efeitos colaterais de doses diferentes de morfina no espaço peridural. Rev Med Aeronaut Bras 1985;38:345-7.

14. Cruz MG, Santana JL. Hemorroidectomia: Estudo de 2.417 pacientes submetidos à cirurgia para tratamento da doença hemorroidária. Rev Bras Coloproct 2006;26:253-68.

15. Imbelloni LE, Vieira EM, Gouveia MA, Cordeiro JA. Raquianestesia posterior para cirurgias anorretais em regime ambulatorial. Estudo piloto. Rev Bras Anestesiol 2004;54:765-69.

16. Cataldo PA, Senagore AJ. Does alpha sympathetic blockade prevent urinary retention following anorectal surgery? Dis Colon Rectum 1991;34:1113-6.

17. Zaheer S, Reilly WT, Pemberton JH, Ilstrup D. Urinary retention after operations for benign anorectal diseases. Dis Colon Rectum 1998;41:696-704.

18. Salvati EP, Kleckner MS. Urinary retention in anorectal and colonic surgery. Am J Surg 1957;94:114-7.

19. Toyonaga T, Matsushima M, Sogawa N, Jiang SF, Matsumura N, Shimojima $Y$, et al. Postoperative urinary retention after surgery for benign anorectal disease: potential risk factors and strategy for prevention. Int J Colorectal Dis 2006;21:676-82.

20. Tammela T, Kontturi M, Lukkarinen O. Postoperative urinary retention. I. Incidence and predisposing factors. Scand J Urol Nephrol 1986;20:197-201.

21. Petros JG, Rimm EB, Robillard RJ, Argy O. Factors influencing postoperative urinary retention in patients undergoing elective inguinal herniorrhaphy. Am J Surg 1991;161:431-3.

22. Keita H, Diouf E, Tubach F, Brouwer T, Dahmani S, Mantz J, et al. Predictive factors of early postoperative urinary retention in the postanesthesia care unit. Anesth Analg 2005;101:592-6.

23. Petros JG, Rimm EB, Robillard RJ. Factors influencing urinary tract retention after elective open cholecystectomy. Surg Gynecol Obstet 1992;174:497-500.

24. Petros JG, Mallen JK, Howe K, Rimm EB, Robillard RJ. Patientcontrolled analgesia and postoperative urinary retention after open appendectomy. Surg Gynecol Obstet 1993;177:172-5.

25. Lau H, Lam B. Management of postoperative urinary retention: a randomized trial of in-out versus overnight catheterization. ANZ J Surg 2004;74:658-61.

26. Darrah DM, Griebling TL, Silverstein JH. Postoperative urinary retention. Anesthesiol Clin 2009;27:465-84.

27. Prasad ML, Abcarian H. Urinary retention following operations for benign anorectal diseases. Dis Colon Rectum 1978;21:490-2.

28. Torda TA, Pybus DA. Comparison of four narcotic analgesics for extradural analgesia. Br J Anaesth 1982;54:291-5.

29. Lanz E, Simko G, Theiss D, Glocke MH. Epidural buprenorphine--a double-blind study of postoperative analgesia and side 


\section{Coloproctology Helio Moreira $J_{\text {, et al. }}$}

effects. Anesth Analg 1984;63:593-8.

30. Ahuja BR, Strunin L. Respiratory effects of epidural fentanyl. Changes in end-tidal $\mathrm{CO}_{2}$ and respiratory rate following single doses and continuous infusions of epidural fentanyl. Anaesthesia 1985;40:949-55.

31. Baldini G, Bagry H, Aprikian A, Carli F. Postoperative urinary retention: anesthetic and perioperative considerations. Anesthesiology 2009;110:1139-57.
32. Borges CJ, de Araujo SJ. Betanecol in the treatment of spinal morphine-induced urinary retention Rev. Bras Anestesiol 2001; 51:245-249.

33. Li S, Coloma M, White PF, Watcha MF, Chiu JW, Li H, et al. Comparison of the costs and recovery profiles of three anesthetic techniques for ambulatory anorectal surgery. Anesthesiology 2000;93:1225-30. 